\title{
WINROB: AN EDUCATIONAL PROGRAM FOR ROBOTICS
}

\author{
J. A. TENREIRO MACHADO and ALEXANDRA M. S. F. GALHANO
}

\begin{abstract}
The paper presents a program for robotics education that runs on standard IBM-PCs under the Microsoft Windows environment. The WinRob package is designed for undergraduate students and emphasises the fundamental aspects of robot modelling and control. The software is self-explanatory and uses menus, dialog boxes and context-dependent on-line help.
\end{abstract}

\section{INTRODUCTION}

In the last two decades robotics has become a common subject in courses of electrical, computer, control and mechanical engineering. Progress in scientific research and developments in industrial applications lead to the appearance of educational programs on robotics, covering a wide range of aspects such as kinematics and dynamics, control, programming, sensors, artificial intelligence, simulation and mechanical design. Nevertheless, courses on robotics require laboratories having sophisticated equipment which pose problems of funding and maintenance.

Computer-based education is a well-established alternative that overcomes some of the referred problems. In this line of thought, university teams and software houses ${ }^{7}$ have developed robot simulation and programming packages running on Apple and IBM-PC computers. Nevertheless, often, computer programs emphasise capabilities such as 3D graphical simulation and the programming language and give a smaller importance to the mathematical aspects of modelling and control. To cover this area, some researchers proposed the adoption of symbolic packages such as Mathematica and MACSYMA ${ }^{11}$ to illustrate robot kinematics and dynamics. However, undergraduate students with no prior experience may have difficulty in getting into the robotics experiments before overcoming the symbolic packages procedures and commands. This state of affairs motivated the development of a computer program highlighting the fundamentals of robot mechanics and control. Given the popularity of Microsoft Windows it was decided to implement the software in this environment using the Microsoft Visual Basic language. The project lead to the WinRob program $12 ! 3$ which was adopted as an educational tool in a first course on robotics. This paper introduces the package and discusses the related educational aspects.

The paper is organised as follows. Section 2 presents a general overview of the software and describes its main features and commands. Section 3 guides us through a typical session for exploring WinRob. Based on the results, 


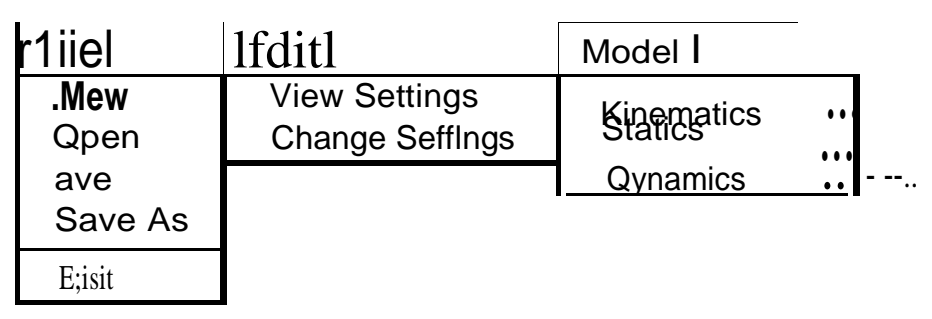

\begin{tabular}{|l|l|l|}
\cline { 2 - 2 } lools I & t.ontrol I \\
\hline .Graphics & eiO & \\
Workspace & Nonlinear & Omputed Torque \\
O.enavlt-Hartenberg & Eorce & Eeedforward \\
Manipulability & & \\
& &
\end{tabular}

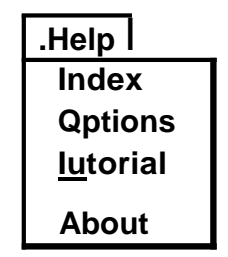

FIG. 1 Selections available in the main menu.

Section 4 discusses future software enhancements. Finally, in Section 5 conclusions are drawn.

\section{OVERVIEW OF THE PROGRAM}

The WinRob educational package was designed to take full advantage of the Windows environment. All the commands and the required parameters are entered through pull-down menus and dialog boxes. The software is intended to be self-explanatory to the extent possible to encourage students exploring the program. For the same purpose, help menus are available throughout the different windows. Several dialog boxes include figures to clarify contextdependent definitions. Experiments are restricted to planar manipulators that is, with two degrees of freedom (dof). This strategy intends to decrement the 'weight' of the graphical simulation and to give importance to the mathematical aspects of kinematics, dynamics and control, while maintaining the program at an introductory level. Moreover, this option allows the use of inexpensive PCs because of the low computational requirements. On the other hand, numerical data files and graphical data files have formats compatible with other Windows applications to allow data interchange and external data calculation.

As usual in Windows programs the top of the screen contains the main menu bar. The top bar includes the entries: File, Edit, Model, Tools, Control and Help. Fig. 1 shows the selections available on each menu. These commands and the related actions are further explained in the next session. 


\section{A TYPICAL CLASSROOM SESSION}

In order to demonstrate the capabilities of the package, the paper now follows a typical classroom session. The tour begins with the definition of the type of robot within three possibilities: the $\mathbf{P P}, \mathbf{R P}$ and RR planar structures (RRotational, P-Prismatic, axis). After selecting the robot type, WinRob pre- sents a dialog box (Fig. 2) for entering the robot numerical parameters, namely the joint limits, the link lengths and masses and the actuator inertias. Later on, these numerical parameters can be viewed/changed and saved using the Edit and File menus, respectively.

The second phase of the session consists on the definition of the robot trajectory. Selecting kinematics, on the Model menu, the student is faced with two options: Teach and Load. Choosing the Teach entry leads to the Pendant Form (Fig. 3) where the user can teach several points of the path (in the joint or, alternatively, in the operational space) using the mouse or the keyboard.

In all graphical forms, point coordinates and its corresponding units can be easily known pointing with the mouse. To complete the trajectory definition the program depicts the Interpolation Form (Fig. 4) for the selection of the interpolation space, the number of interpolation points and the Acceleration Form (Fig. 5) for the time evolution of positions, velocities and accelerations.

The student can analyse the non-linear effect of the kinematics in the interpolation method. During the calculation, a graphical form (Fig. 6) depicts the

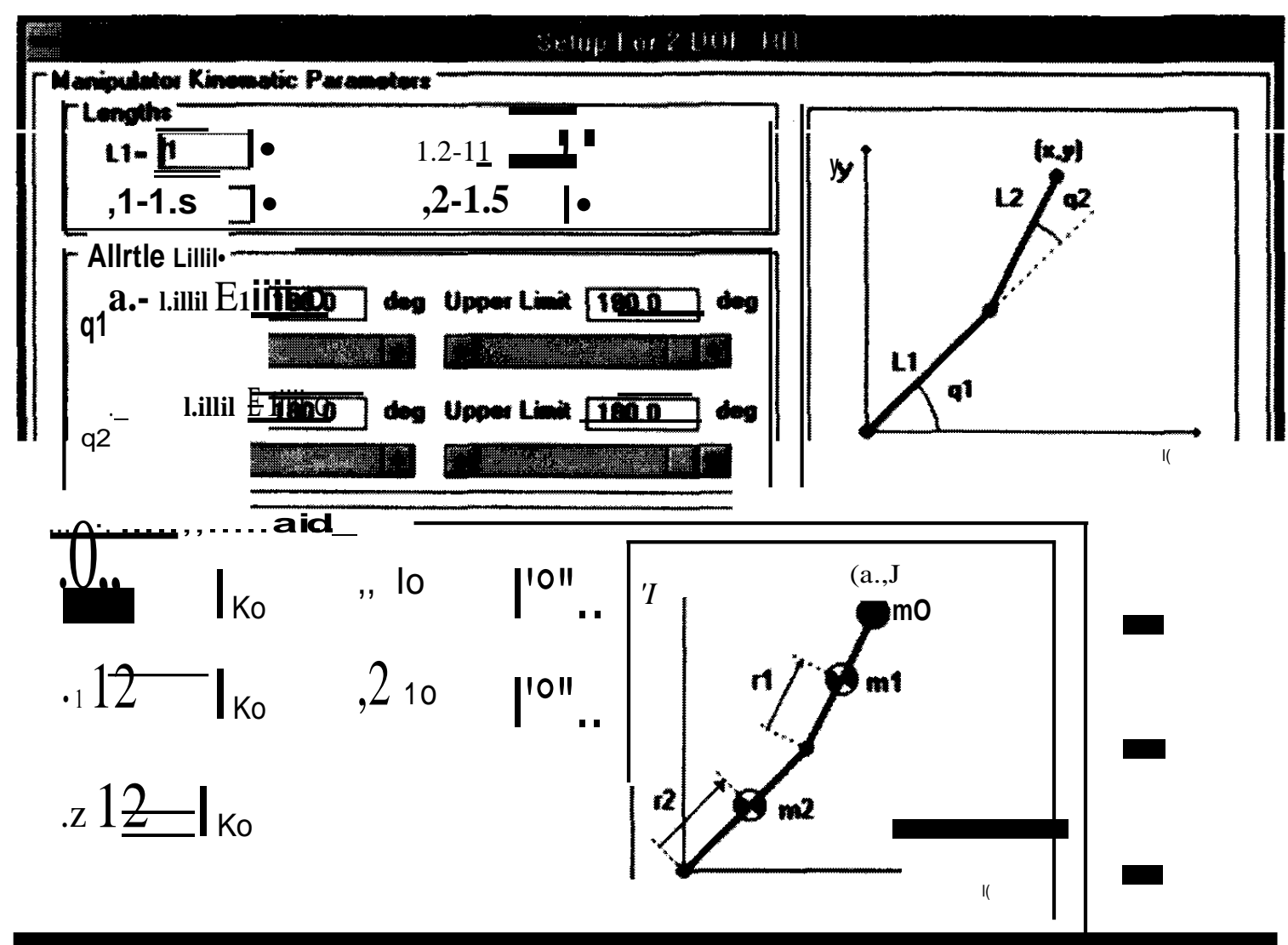

FIG. 2 Setup of a robot structure. 


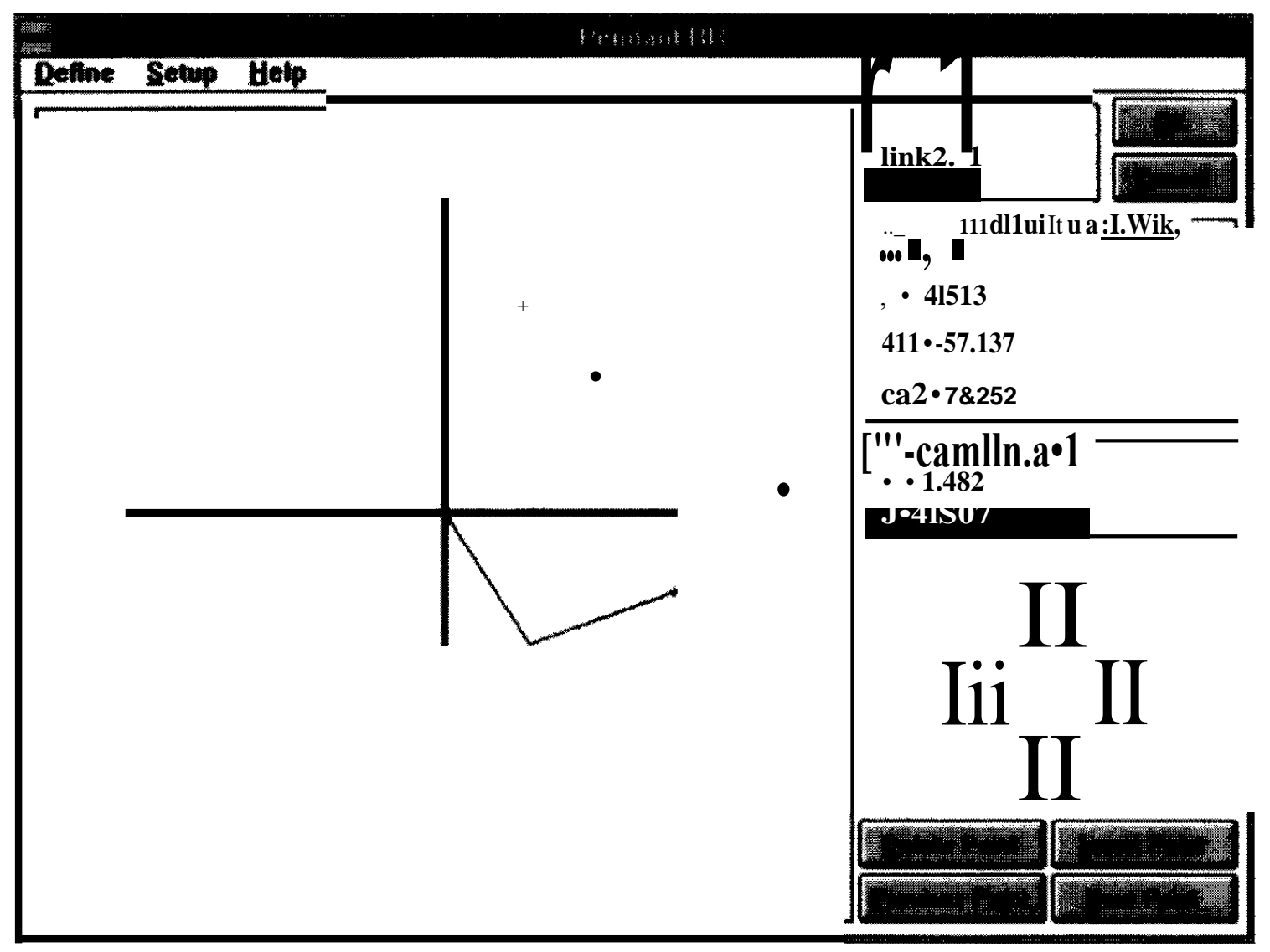

FIG. 3 Teaching trajectory points.

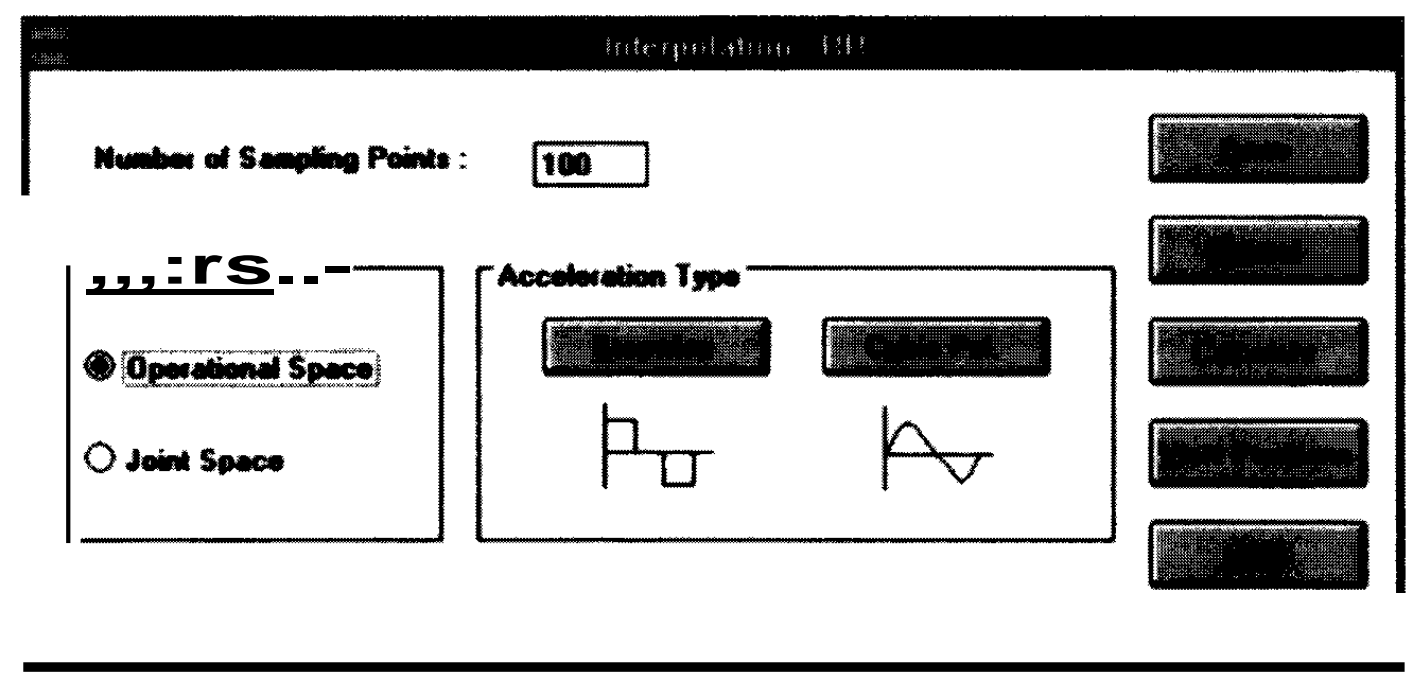

FIG. 4 Definition of the trajectory interpolation.

successive interpolation points, both in the cartesian and joint spaces. After defining the trajectory, the inverse dynamics option is activated and the time evolution of the corresponding joint driving torques can be viewed through the Graphics option in the Tools menu.

On the other hand, the entries Statics and (Direct) Dynamics in the menu 


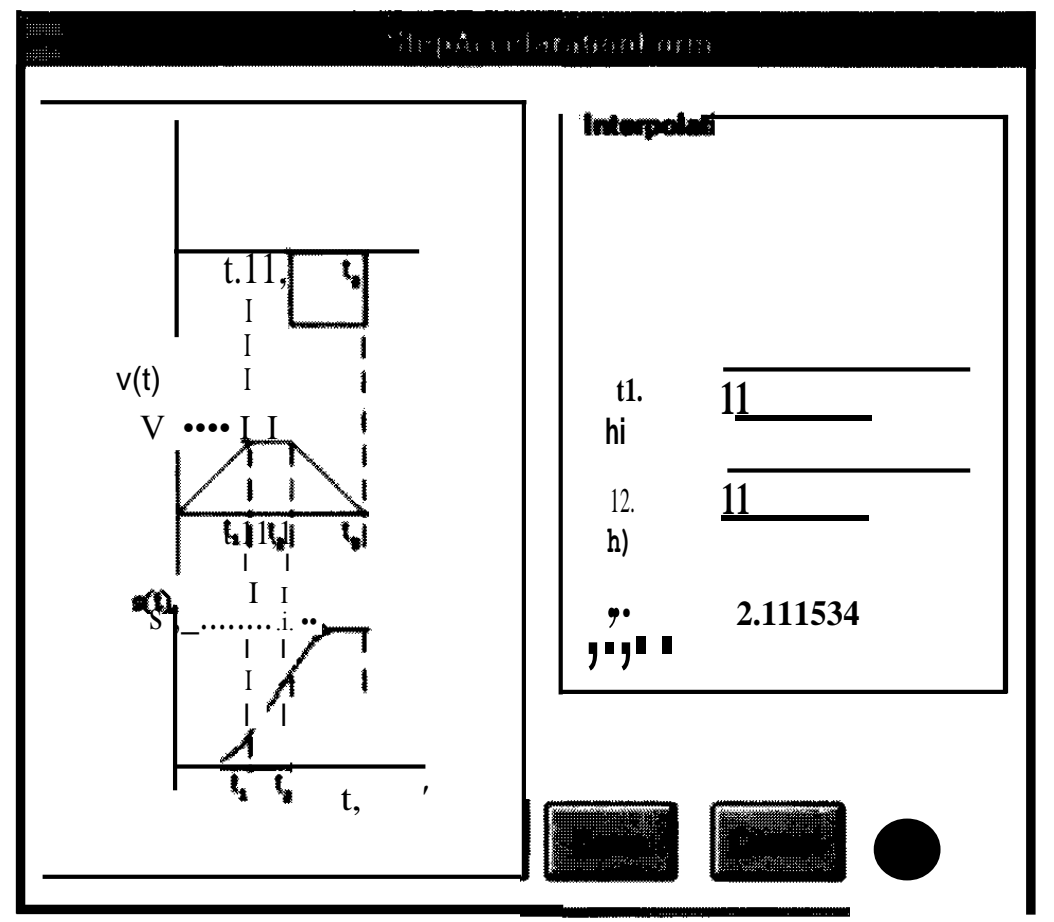

FIG. 5 Definition of the time evolution of the variables.

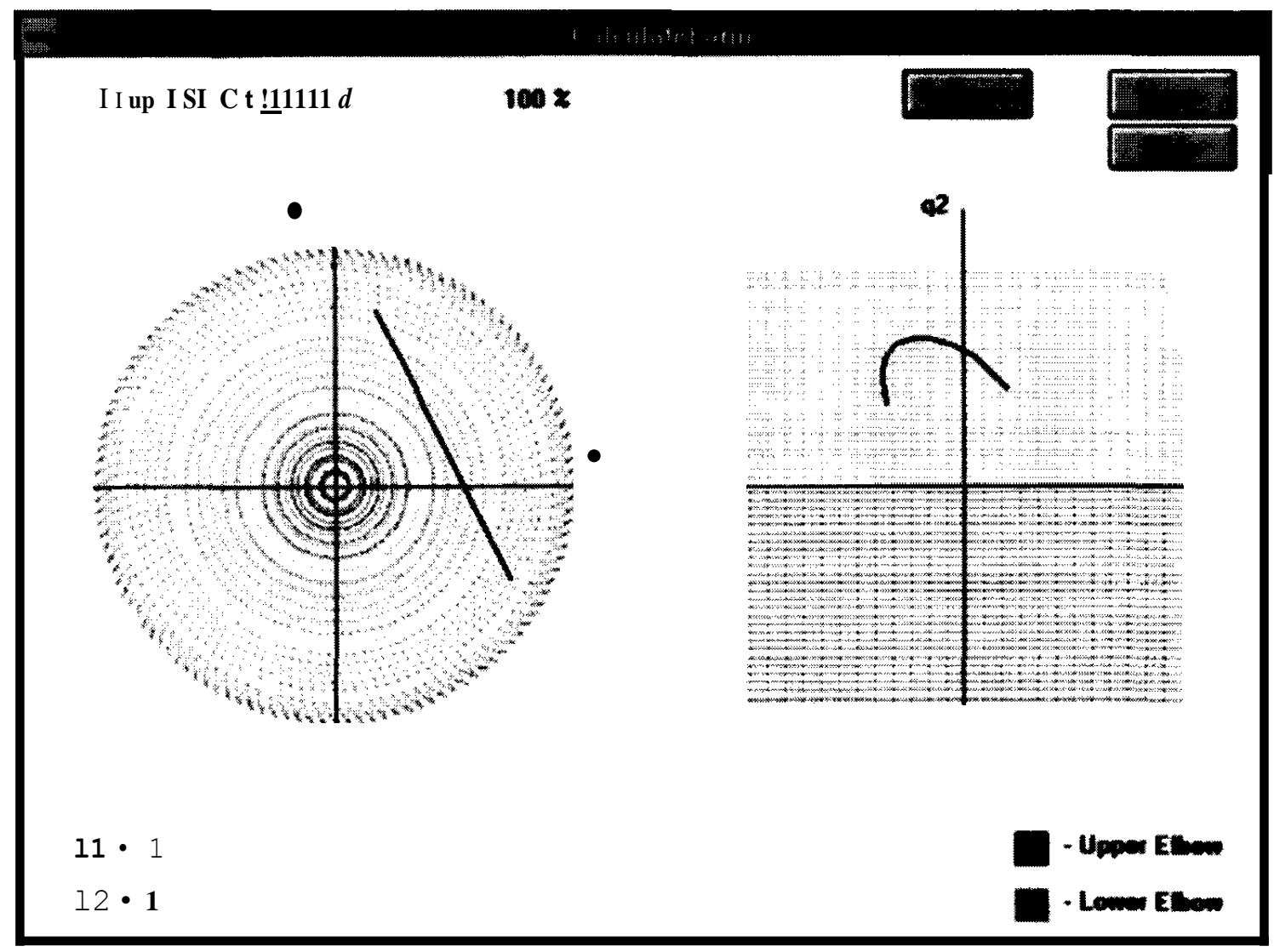

FIG. 6 Trajectory interpolation. View in the operational and joint spaces. 
Model become activated. Both entries allow the Teach and Load options. In the first case, the amplitude versus time evolution of the forces/torques can be taught as a piecewise linear function approximation whose points are inserted/deleted through the mouse (Fig. 7). In the second case, a numerical data can be loaded from an external software application.

The third phase of the lesson consists on selecting the Graphics on the Tool menu. In this case the student can view (Fig. 8) the evolution (both in the time and phase plane domains) of the variables. During the rest of the session the kinematic, dynamic and control variables can be viewed, printed and compared through the Graphics option. In order to simplify the identification of each case, the toolbar has buttons that are activated when the corresponding variables are calculated.

The Tools menu includes other entries such as Workspace and Manipulability (Fig. 9) for the analysis of the robot properties. The Denavit-Hartenberg entry was designed as a 'customized calculator' (Fig. 10). In this sense, the student can enter numerical values and view the corresponding robot configuration. Planar manipulators represent a limit to the scope of the Denavit-Hartenberg formalism that, in fact, are more relevant for six dof structures. Nevertheless, WinRob is an introductory program that may be followed by a more sophisticated package.

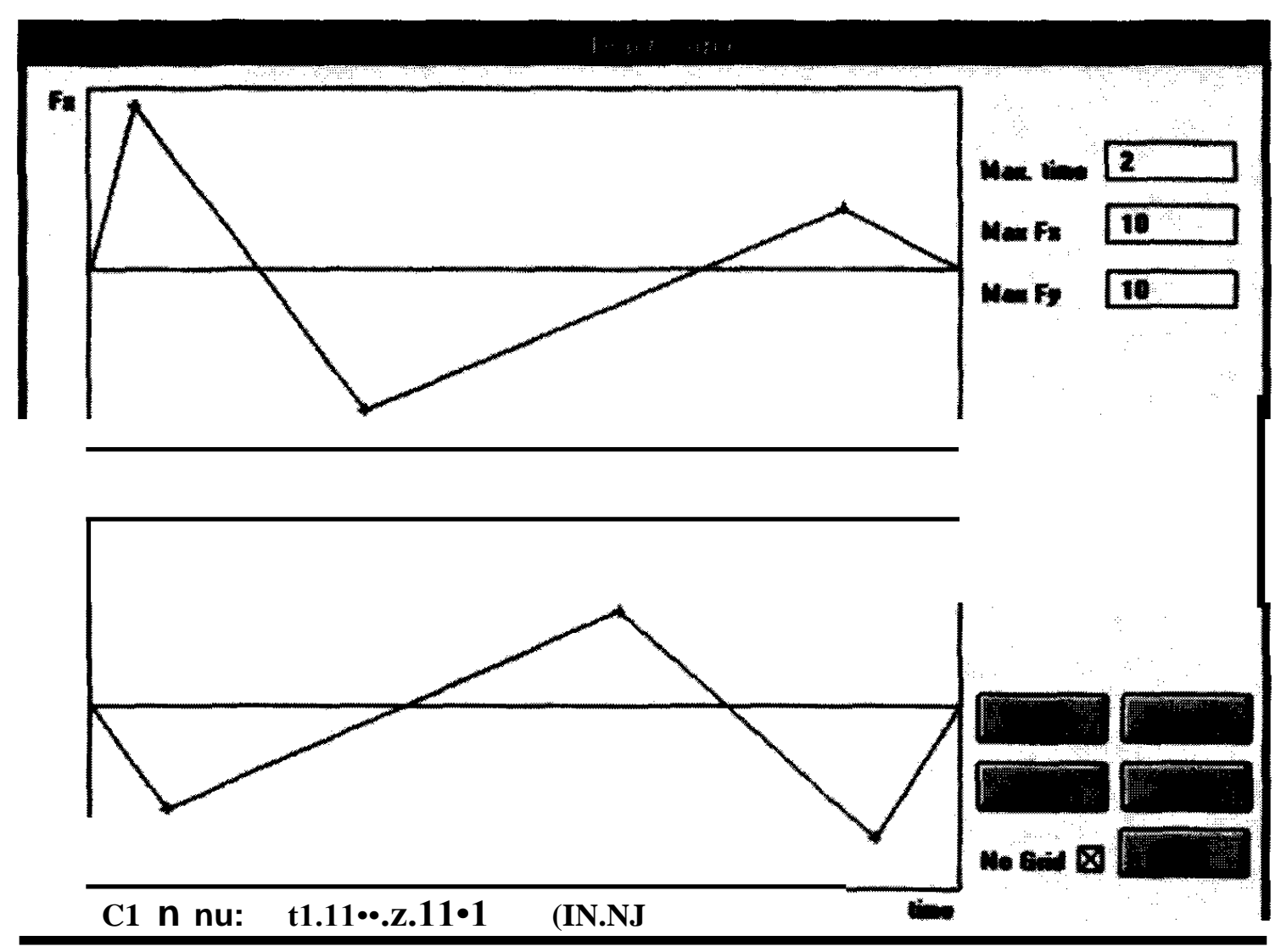

FIG. 7 Teaching static forces. 


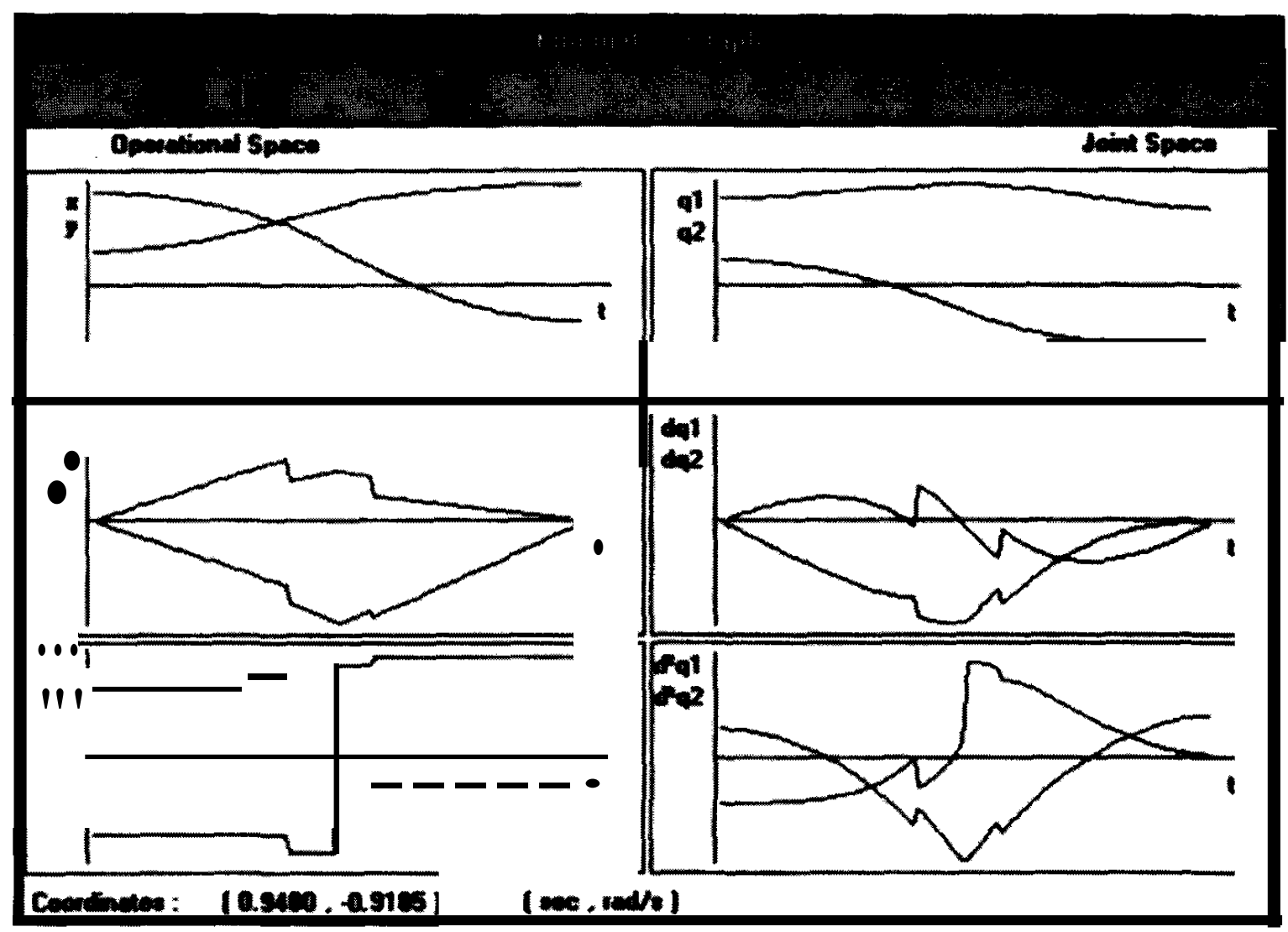

FIG. 8 Using the Graphics selection to view the time evolution of positions, velocities and accelerations in the operational and joint spaces.

The Control menu allows the choice of several controllers. In this case, the user can investigate the effects of finite sampling frequencies, gain tuning and imperfect modelling. Moreover, the student can easily experiment and compare the performances of different algorithms. For example, Fig. 11 depicts the main form for the non-linear model-based computed torque controller.

At any time during the worksession users can get on-line help in each form. Nevertheless, WinRob has a separate Help menu where additional guidelines can be found. A Tutorial option (Fig. 12) allows the study of the main formulae and definitions adopted in the package.

\section{FUTURESOFTWAREENHANCEMENTS}

WinRob is planned to include several additional educational features. In the robot definition, selection on structures such as counterweights and parallelogram linkages will allow the study of compensation schemes leading to a new dynamics $^{14}$. The Tools menu will include an entry for the analysis of different methods of calculation of the inverse dynamics ${ }^{15}$. In this perspective, the student can investigate numerical recursive methods such as the Lagrange-Euler, the Newton-Euler and adoption of symbolic formulae. The analysis of the computational load posed by the different algorithms will motivate students for the aspects of software optimisation for real-time applications.

The present version of WinRob has not yet made available the option for 


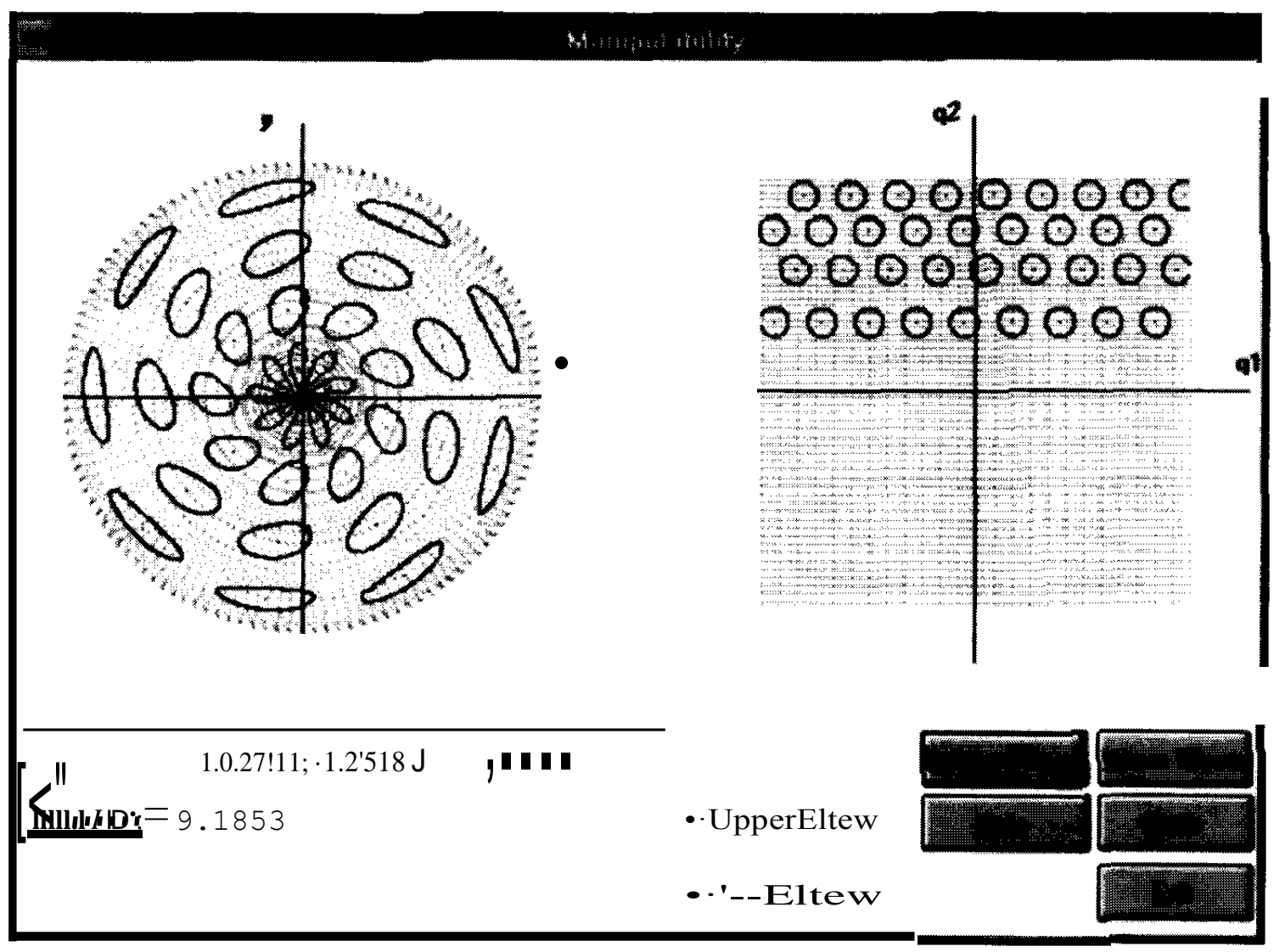

FIG. 9 Analysis of the robot manipulability.

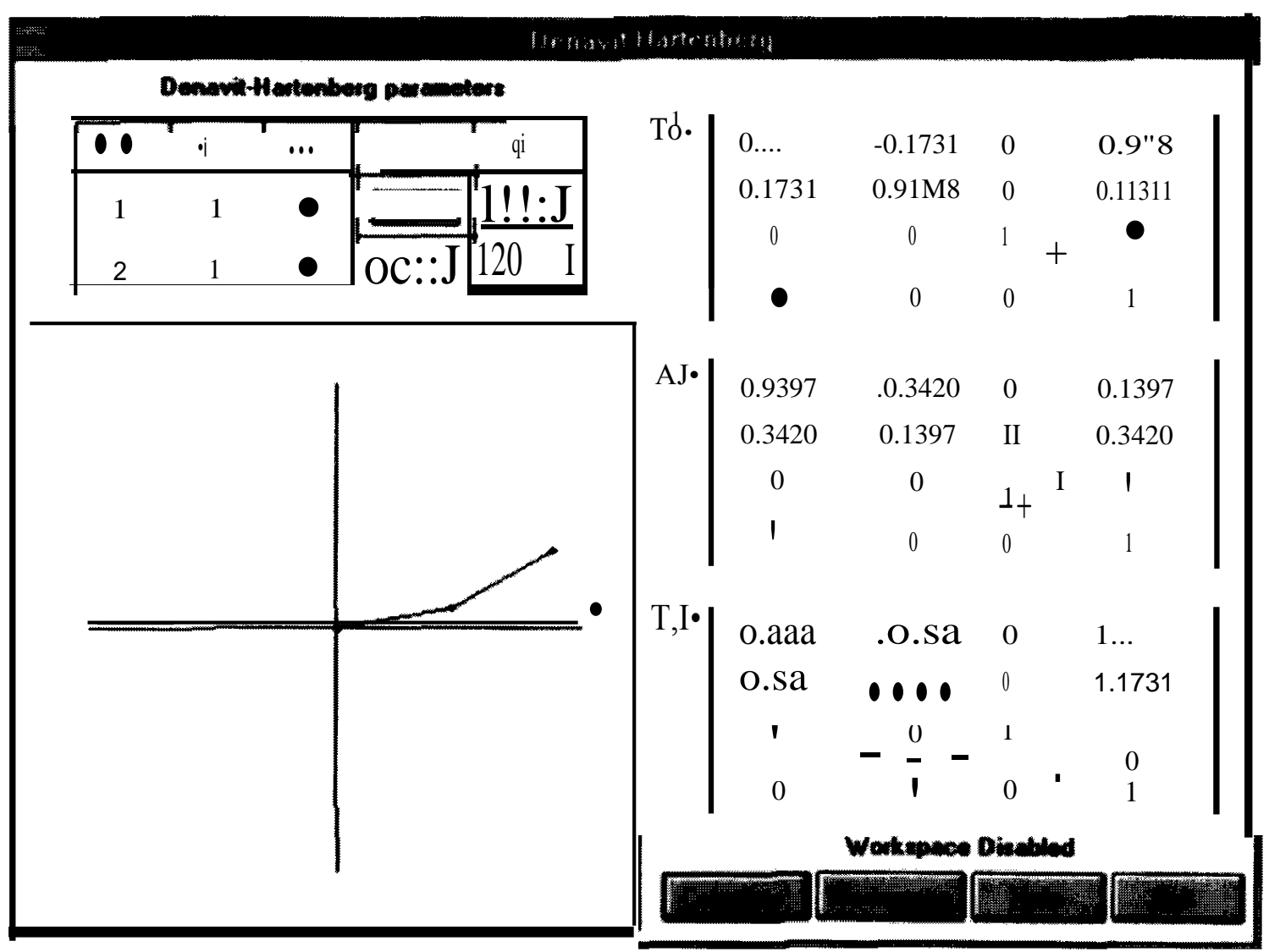

FIG. 10 Exploring the Denavit-Hartenberg 'calculator' in the Tools menu. 


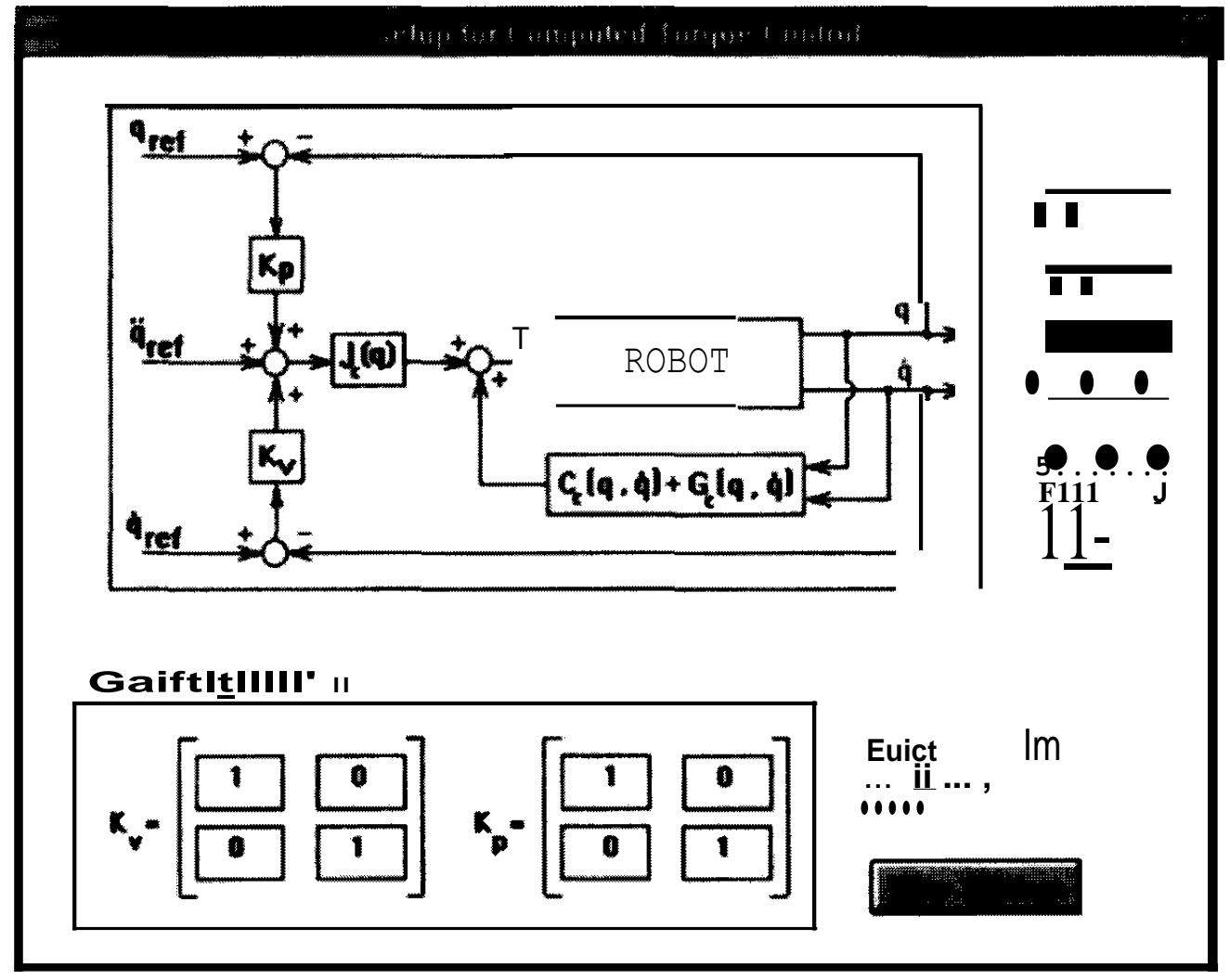

FIG. 11 Initialising the setup form of the computed torque algorithm in the Control menu.

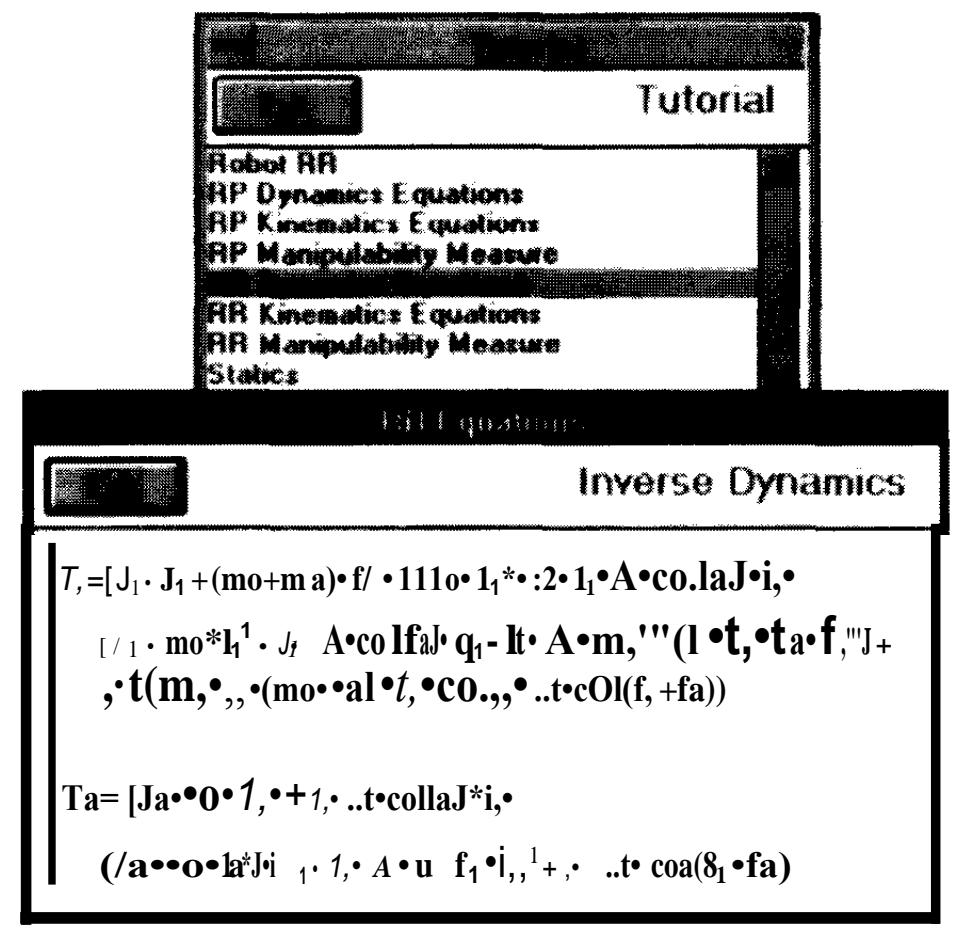

FIG. 12 Using the option Tutorial in the Help menu. 
force control algorithms. This limitation is due to the difficulty in defining the most adequate educational choice between the plethora of possible algorithms and models both for the controller and the environment. Based on the authors' experience, the 'hybrid architecture' is being implemented for the force/position controller and a simple linear model for the environment consisting of a massdamping-spring system. Other options such as the 'impedance controller' or environment phenomena including non-linear friction seem less appropriate for an introductory package. On the other hand, the definition of the quantifying effects of the A/D and D/A converters or the introduction of actuator models (e.g. saturation and hysteresis) are still under evaluation. In fact, a balance must be made between the adoption of a 'professional' software and a introductory program for students.

A more important educational aspect is the students' introduction to WinRob. In this line of thought, a five minute VHS-video tape has already been prepared for teacher use. Moreover, a small set of exercises/experiments for WinRob is presently being developed.

As stated previously, WinRob is an introductory program that is limited to simple planar manipulators. In order to extend the concepts to six dof robots, a complementary package (RobLib) is presently being developed with a library of models and algorithms for standard industrial manipulators ${ }^{6}{ }^{6}$. This robotic library is also implemented in Visual Basic for Windows to allow simple data interchange through the programs.

\section{CONCLUSIONS}

A program for robotics education has been presented. WinRob is a package that runs on standard IBM-PCs under the Microsoft Windows environment. The program is designed to be used at an introductory level for undergraduate students and emphasises the aspects of robot mathematical modelling. The software is self-explanatory and uses menus, dialog boxes with figures and context-dependent on-line help. In this perspective, students are motivated to investigate the kinematics, dynamics, trajectory planning and control in order to gain insight into robotics, before getting into expensive laboratory experiments with real robots.

Those interested in obtaining the WinRob package should send their request to the first author.

\section{REFERENCES}

[1] Derby, S., In 'Position: simulating robotic workcells on a micro', Computers in Mechanical Engineering, pp. 34-37 (Sept. 1986)

[2] White, R. B., Read, R. K., Koch, M. C. and Schilling, R. J., 'A graphics simulator for a robotic arm', IEEE Trans. on Education, 32, No. 4, pp. 417-429 (Nov. 1989)

[3] Raz, T., 'Graphics robot simulator for teaching introductory robotics', IEEE Trans. on Education, 32, No.2, pp. 153-159 (May 1989)

[4] Parkin, R. E., 'An interactive robotic simulation package', Simulation, 56, No. 5, pp. 337-345 (May 1991)

[5] Eydgahi, A. M. and Sheehan, J. J., 'A computer animation of robotic manipulators and workcells', IEEE Control Systems, 11, No. 4, pp. 56-59 (June 1991) 
[6] WorkSpace User-Manual, Robot Simulations, Newcastle-Upon-Tyne, England (1989)

[7] SYMORO: Software Package of SYmbolic MOdelling of RObotics, Rapid Data Ltd (1990)

[8] Lloyd, J. and Hayward, V., 'Kinematics of common industrial robots', Robotics and Autonomous Systems, 4, No. 2, pp. 169-191 (1988)

[9] Leu, M. C. and Wang, Y. S., 'Studying robot kinematics and dynamics with the aid of MATHEMATICA', Int. J. of Mechanical Engineering Education, 19, No. 3, pp. 213-228 (1990)

[10] Vira, N. and Tunstel, E., 'Use of symbolic computation in robotics education', IEEE Trans. on Education, 35, No. 1, pp. 18-30 (Feb. 1992)

[11] Nethery, J. F. and Spong, M. W., 'Robotica: a mathematica package for robot analysis', IEEE Robotics \& Automation Magazine, 1, No. 1, pp. 13-20 (March 1994)

[12] Tenreiro Machado, J. A. and Galhano, Alexandra M., 'A program for teaching the fundamentals of robot modelling and control', IFAC Symposium on Robot Control '94, Capri, Italy (Sept. 1994)

[13] Tenreiro Machado, J. A. and Galhano, Alexandra M., 'WinRob: a program for reaching robot mechanics and control', IEEE/IFAC/ASME/JSME Int. Conj. on Recent Advances in Mechatronics, Istanbul, Turkey (Aug. 1995)

[14] Tenreiro Machado, J. A., Martins de Carvalho, J. L. and Galhano, Alexandra M., 'Analysis of robot dynamics and compensation using classical and computed torque techniques', IEEE Trans. on Education, 36, No. 4, pp. 372-379 (Nov. 1993)

[15] Tenreiro Machado, J. A. and Galhano, Alexandra M., 'Benchmarking computer systems for robot control', IEEE Trans. on Education, 38, No.3, pp. 205-210 (Aug. 1995)

[16] Megahed, S. M., Principles of Robot Modelling and Simulation, John Wiley (1993)

\section{ABSTRACTS - FRENCH, GERMAN, SPANISH}

\section{WinRob: un programme educatif en robotique}

Cet article presente un programme d'enseignement de la robotique qui tourne sur IBM-PC dans un environnement Microsoft Windows. L'ensemble logiciel WinRob est con u pour etudiants et met !'accent sur les aspects fondamentaux de la modelisation et du controle en robotique. Le logiciel est auto-explicatif et utilise des menus, boites de dialogue et aide en ligne dependante du contexte.

\section{WinRob: ein Schulungsprogramm fur Robotik}

Der Artikel stellt ein Programm zur Robotik-Schulung dar, das auf Standard IBM-PCs im Microsoft Windows Urnfeld liiuft. Das WinRob Paket ist filr Studenten der unteren Semester ausgelegt und betont die fundamentalen Asspekte des Modellierens und der Steuerung von Robotern. Die Software erkliirt sich von selbst und verwendet Menus, Dialogfenster und vom Zusammenhang abhiingige On-Line Hilfe.

\section{WinRob: un programa educacional para robotica}

El articulo presenta un programa educacional de rob6tica que funciona en IBM-PCs bajo el entorno Microsoft Windows. El programa WinRob esta disefiado para su uso por estudiantes y pone enfasis en los aspectos fundamentales de modelizaci6n y control de robots. El software utiliza menus, ventanas de dialogo y ayuda en linea dependiente de contexto. 